\title{
RESEARCH
}

Open Access

\section{Dyslipidemia and cardiovascular disease risk among the MASHAD study population}

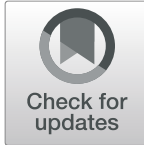

\author{
Mahshad Hedayatnia ${ }^{1 \dagger}$, Zahra Asadi ${ }^{1,2 \dagger}$, Reza Zare-Feyzabadi ${ }^{3 \dagger}$, Mahdiyeh Yaghooti-Khorasani ${ }^{3}$, \\ Hamideh Ghazizadeh ${ }^{2,3,4}$, Roshanak Ghaffarian-Zirak ${ }^{3}$, Abolfazl Nosrati-Tirkani ${ }^{3}$, Maryam Mohammadi-Bajgiran ${ }^{3}$, \\ Mohadese Rohban ${ }^{3}$, Fatemeh Sadabadi ${ }^{3}$, Hamid-Reza Rahimi ${ }^{3}$, Marzieh Ghalandari ${ }^{3}$, \\ Mohammad-Seddigh Ghaffari ${ }^{5}$, Asa Yousefi ${ }^{5}$, Elnaz Pouresmaeili ${ }^{5}$, Mohammad-Reza Besharatlou ${ }^{5}$, \\ Mohsen Moohebati ${ }^{6}$, Gordon A. Ferns ${ }^{7}$, Habibollah Esmaily ${ }^{8^{*}}$ and Majid Ghayour-Mobarhan ${ }^{3,4^{*}}$ (D)
}

\begin{abstract}
Introduction: Dyslipidemia may be defined as increased levels of serum total cholesterol (TC), low-density lipoprotein cholesterol (LDL-C), triglycerides (TG), or a decreased serum high-density lipoprotein cholesterol (HDL-C) concentration. Dyslipidemia is an established risk factor for cardiovascular disease (CVD). We aimed to investigate the association of dyslipidemia and CVD events among a population sample from Mashhad, in northeastern Iran.

Material and methods: This prospective cohort study comprised a population of 8698 men and women aged 3565 years who were recruited from the Mashhad Stroke and Heart Atherosclerotic Disorder (MASHAD) study. Socioeconomic and demographic status, anthropometric parameters, laboratory evaluations, lifestyle factors, and medical history were gathered through a comprehensive questionnaire and laboratory and clinical assessment for all participants. Cox regression model and 95\% confidence interval (Cl) were used to evaluate the association of dyslipidemia and its components with CVD incidence.
\end{abstract}

Results: After 6 years of follow-up, 233 cases of CVD (including 119 cases of unstable angina [US], 74 cases of stable angina [SA], and 40 cases of myocardial infarction [MI]) were identified in the study population. Unadjusted baseline serum LDL-C, TC, and TG levels were positively associated with the risk of total CVD events among the entire population (HR: 1.54, 95\% Cl: 1.19-2; P-value< 0.01; HR: 1.53; 95\% Cl: 1.18-1.98; P<0.01; HR: 1.57; 95\% Cl: 1.27-2.03; $P<0.01$, respectively). However, after adjusting for confounding factors (age, body mass index [BMI], family history of CVD, smoking status [non-smoker, ex-smoker and current smoker], lipid lowering drug treatment, antihypertensive drug treatment, hypertension, healthy eating index [HEI], total energy intake, and presence of diabetes mellitus), a significant direct association only remained between TC and Ml risk in men (HR: 2.71; 95\%Cl: 1.12-6.57; $P$-value< 0.05).

Conclusion: In the present study, TC baseline level was significantly associated with the risk of MI among men.

Keywords: Dyslipidemia, Cardiovascular disease, Stable angina, Unstable angina, Myocardial infarction, Total cholesterol

\footnotetext{
* Correspondence: Esmailyh@mums.ac.ir; ghayourm@mums.ac.ir

${ }^{\dagger}$ Mahshad Hedayatnia, Zahra Asadi and Reza Zare-Feyzabadi contributed equally to this work.

${ }^{8}$ Social Determinants of Health Research Center, Mashhad University of

Medical Sciences, Mashhad, Iran

${ }^{3}$ Metabolic Syndrome Research Center, School of Medicine, Mashhad

University of Medical Sciences, Mashhad, Iran

Full list of author information is available at the end of the article
}

(c) The Author(s). 2020 Open Access This article is distributed under the terms of the Creative Commons Attribution 4.0 International License (http://creativecommons.org/licenses/by/4.0/), which permits unrestricted use, distribution, and reproduction in any medium, provided you give appropriate credit to the original author(s) and the source, provide a link to the Creative Commons license, and indicate if changes were made. The Creative Commons Public Domain Dedication waiver (http://creativecommons.org/publicdomain/zero/1.0/) applies to the data made available in this article, unless otherwise stated. 


\section{Introduction}

Dyslipidemia is characterized by an elevation of serum total cholesterol (TC), low-density lipoprotein cholesterol (LDL-C), or triglycerides (TG) and reduced serum high-density lipoprotein cholesterol (HDL-C) concentration [1-3] and is these are routinely assessed for the purpose of assessing cardiovascular risk. The prevalence of dyslipidemia varies geographically; although, it has been estimated that more than $50 \%$ of the adult population has dyslipidemia worldwide [4-6]. The prevalence of hypercholesterolemia, hypertriglyceridemia, high levels of LDL-C, and low levels of HDL-C are reported to be $41.6,46.0,35.5$, and $43.9 \%$, respectively in both sexes in the Iranian population [7]. Darroudi et al. have recently reported the prevalence of dyslipidemia among a subsample of Iranian adults to be 83 and $87 \%$ in the total population and CVD patients, respectively [8].

CVD is a chronic non-communicable disease and one of the most important causes of death and disability [9]. The prevalence of CVD events is increasing globally [9, $10]$. It is the leading cause of mortality in Iran, accounting for $50 \%$ of total mortality and $79 \%$ of deaths due to chronic diseases [9]. Atherosclerosis is the major underlying cause of CVD [11]; the World Health Organization (WHO) definition of CVD includes: coronary heart disease, cerebrovascular disease, rheumatic heart disease, myocardial infarction (MI), stable angina (SA), unstable angina (UA), and other conditions [11]. Public health organizations globally have focused on reducing modifiable CVD risk factors to control the rising prevalence of CVD and its risk factors; such as hypertension (HTN), unhealthy diet, obesity and dyslipidemia [3, 10, 12-14]. A high-fat and high-calorie diet can cause dyslipidemia and thereafter endothelial dysfunction [15]. Serum TG, TC, LDL-C, HDL-C, TC/HDL-C, and LDL-C/HDL-C ratios are independent predictors of CVD risk. Currently, the principal objective in the management of dyslipidemia is to reduce serum LDL-C levels [16].

Components of the circulating lipid profile, but particularly modified LDL-C, may be deposited within the tunica intima of the artery wall, and are involved in the subsequent atherogenic process [17-19]. The benefits of reducing plasma LDL-C concentrations on CVD risk are particularly evident in subjects with familial hypercholesterolemia [20]. Although the association of high TG levels with the occurrence of cardiovascular disease (CVD), especially atherosclerotic CVD, has been well documented in large cohort studies [21], its role as an independent CVD risk factor remains controversial [20]. The reason for this is that an elevated TG concentration is associated with higher concentrations of the atherogenic small dense LDL particles and lower HDL-C concentrations [20].

Whilst it has been proposed that HDL-C is protective against CVD, partially related to its role in reverse cholesterol transport $[2,22]$, some studies have reported that high or normal levels of HDL-C are not protective against CVD events [23]. A single serum HDL-C level reflects the HDL-C pool rather than its functionality [23]. Modified forms of the various protein components of HDL, perhaps generated by oxidative stress, may reduce the ability of HDL to take part in reverse transport [23].

Whilst several studies have demonstrated the association of serum lipid levels and the occurrence of CVD in western population samples [24-27], there, are relatively few in Asian populations. We aimed to define the association between all components of dyslipidemia and the incidence of CVD events among a population sample of adults from north-eastern Iran.

\section{Materials and methods Study population}

Participants were recruited as part of the Mashhad stroke and heart atherosclerotic disorder (MASHAD) cohort study. The MASHAD study is a prospective cohort study, comprising 9704 men and women aged 3565 years from the city of Mashhad, in the country of Iran. This study was initiated in 2010 and was planned to evaluate various CVD risk factors (code no: 85134). The incidence of CVD was assessed among participants at several follow-up time-points (2011, 2014 and 2016). Individuals who were lost to attendance at the different stages of follow-up or those with missing data regarding lipid profile components (including LDL-C, TC, TG, and HDL-C) were excluded from the study. Finally, 8698 subjects including 235 individuals with CVD, and 8465 individuals without overt CVD were included in the data analysis. The Human Research Ethics Committee of Mashhad University of Medical Sciences (MUMS) reviewed and approved the study. All participants provided written informed consent.

\section{Diagnosis of cardiovascular diseases}

The occurrence of CVD among participants at follow-up was ascertained by taking a detailed medical history, followed by a physical examination by a specialist Cardiologist. Electrocardiograms were checked by the cardiologist for the evidence of alterations in $\mathrm{P}, \mathrm{QRS}, \mathrm{T}$ and especially $Q$ wave by using the Minnesota Code [28, 29]. If the cardiologist suspected a diagnosis of CVD, further examinations were undertaken that included; echocardiography, stress echocardiography, radioisotope, angiography, Computed Tomography (CT) angiography, and Exercise Tolerance Test (ETT). The definitive diagnosis was based on the consensus agreement of a panel of experts among 235 subjects including 120 subjects with unstable angina, 75 subjects with stable angina, and 40 subjects with myocardial infarction. Finally, we excluded 
2 CVD patients due to missing data regarding lipid profile (including 1 subject with unstable angina and 1 subject with stable angina).

\section{Anthropometric assessments}

Height, weight, body mass index (BMI), waist circumference (WC), hip circumference (HC), waist-to-hip ratio (WHR), and mid-upper arm circumference (MAC) were measured according to the standardized protocols [30] in all participants. Height $(\mathrm{cm})$, waist circumference $(\mathrm{cm})$, hip circumference $(\mathrm{cm})$, and mid-upper arm circumference $(\mathrm{cm})$ were measured to the nearest millimeter using a tape measure. Weight $(\mathrm{kg})$ was measured to the nearest $0.1 \mathrm{~kg}$ using electronic scales. The BMI was calculated by dividing weight $(\mathrm{kg})$ to height squared $\left(\mathrm{m}^{2}\right)$ [30]. Interpretation of the mean BMI was admitted by the standardized protocols [31,32]. Waist-to-hip ratio (WHR) was calculated by dividing waist circumference to hip circumference [30].

\section{Laboratory evaluation}

Blood samples of all participants were collected after a 14 h overnight fast. Serum TG, low-density lipoprotein cholesterol (LDL-C), high-density lipoprotein cholesterol (HDL-C), and total cholesterol (TC), were estimated using enzymatic methods on an automated analyzer; fasting blood glucose (FBG) was also measured by enzymatic methods on an autoanalyser. Dyslipidemia was defined as $\mathrm{TC} \geq 200 \mathrm{mg} / \mathrm{dl}$, or $\mathrm{TG} \geq 150 \mathrm{mg} / \mathrm{dl}$, or LDL$\mathrm{C} \geq 130 \mathrm{mg} / \mathrm{dl}$, or $\mathrm{HDL}-\mathrm{C}<40 \mathrm{mg} / \mathrm{dl}$ (for men) and HDL-C $<50$ (for women) [5, 33, 34]. Diabetes was defined as $\mathrm{FBG} \geq 126 \mathrm{mg} / \mathrm{dl}[5,35]$.

\section{Blood pressure assessment}

Systolic blood pressure (SBP) and diastolic blood pressure (DBP) were measured using calibrated mercury sphygmomanometers. HTN in the cases who had high blood pressure was defined as systolic blood pressure $\geq$ $140 \mathrm{mmHg}$ or diastolic blood pressure $\geq 90 \mathrm{mmHg}$ [36].

\section{Assessment of physical activity level (PAL)}

The questionnaire used for assessing physical activity was based on the James and Schofield human energy requirements equations and was completed by all subjects. Questions were divided into three parts that included activities in work time, non-work time, and in bed [3739].

\section{Dietary intake assessment and healthy eating index calculation}

The dietary intake and total energy consumption (kcal/ day) of all participants were determined by using a validated 65-items food frequency questionnaire (FFQ), which was completed by a trained nutritionist for the entire population of the study at baseline. Each item of the FFQ included the portion size and five frequency groups (consumption per day, per week, per month, rarely, and never). The consumption of each food item (gram per day) was obtained by multiplying the portion size and reported frequency of intake of that food item [40]. The intra-class correlation coefficient (ICC) which represents a good validity of most food items was calculated by the agreement of the FFQ and 24-h recall. A Pearson's correlation coefficient indicated good reproducibility of the FFQ by a correlation between FFQ1 and FFQ2 that were completed with a definite interval for a sample of the participants [41]. To assess diet quality, the Healthy-Eating-Index2010 (HEI-2010) was used as a reliable tool [42]. The scores for each component ranged from zero to 10 points. The protein, foods, vegetables, and fruits have a maximum score of 5 points. Empty calorie components' scores are assigned up to 20 points. The summation of the component scores can reach up to 100 points. The mean total healthy eating index-2010 scores were used in the results section. The HEI index includes multiple component systems scoring to characterize the quality of diet [43]. The latest version of HEI is called HEI-2015. It contains 13 components that reflect the different food groups and critical recommendations in the 2015-2020 Dietary Guidelines for Americans, including total fruit, whole fruit, vegetables, greens and beans, whole grains, dairy, total protein foods, seafood and plant proteins, and fatty acids (FAs). The second group assesses dietary components that should be consumed in moderation, namely, refined grains, sodium, and empty calories. Empty calories are defined as energy consumption from added sugars, alcohol, and solid fats [44]. In this study, we used a version of HEI 2010 [45].

\section{Assessment of other variables}

Demographic and socioeconomic characteristics (e.g. age, sex, marriage status and education), lifestyle data including smoking (current smoker, ex-smoker and nonsmoker), drug history (DH) (include lipid lowering drug and anti-hypertensive drug), and family history (FH) of CVD for all participants were collected by health care professionals and a nurse interview.

\section{Statistical analysis}

All statistical analyses were performed using SPSS version 20 (SPSS, Chicago, IL). The chi-square, analysis of variance (ANOVA), and Kruskal-Wallis tests were used to report distribution differences for qualitative and quantitative (normal and non-normal) data, respectively among defined groups of the study population. Hazard ratios (HRs) and 95\% confidence intervals (CIs) were calculated using cox regression to obtain the association of 
dyslipidemia and CVD risk. The calculated HRs were adjusted for potential confounders including age, total energy intake, HEI, body mass index (BMI), family history of CVD, smoking status (non-smoker, ex-smoker and current smoker), lipid lowering drugs, anti-hypertensive drug treatment, presence of diabetes mellitus, and hypertension. A $p$-value of less than 0.05 was considered as significant.

\section{Results}

After excluding 1006 persons who were lost to followup, or those with missing data, we included 8698 participants of the MASHAD cohort study in the final analysis. Of these, 233 subjects (including 119 cases of unstable angina, 74 cases of stable angina, and 40 cases of $\mathrm{MI}$ ) had suffered a CVD event and 8465 subjects were considered to be healthy controls, and were included in the final data analysis.

Participants were compared based on the occurrence of CVD (Table 1). The percentage of males within the case and control groups were 47 and $41 \%$, respectively. Subjects who had CVD events were older than the control group ( $p$-value $<0.001)$. We also found that CVD patients tended to be less well educated, more had a positive smoking history (ex-smoker and current smokers) compared to healthy controls ( $p$-value $<0.001)$. Weight, BMI, waist circumference (WC), and waist-tohip ratio (WHR) were higher in the CVD patients ( $p$ values $<0.01)$ while, healthy participants had higher levels of physical activity level $(\mathrm{PAL})(p$-value $=0.001)$. The levels of serum TC, TG, LDL-C and FBG were all higher in CVD patients ( $p$-values $<0.01)$, whereas serum HDL-C concentrations were lower ( $p$-value $<0.001)$. Systolic and diastolic blood pressures were higher in CVD patients. The prevalence of dyslipidemia, hypertension, diabetes, and family history of CVD were greater in CVD patients $(p$-value $<0.001)$. Lipid lowering drug and anti-hypertensive drug treatment were higher in the CVD patients than for the control group ( $p$-value < 0.001).

In Table 2, we compare all participants with or without dyslipidemia; 7424 participants had dyslipidemia and 1273 did not. Participants with dyslipidemia were older, heavier, shorter, tended not to be married, had higher mean BMI, WC, hip circumference (HC), and WHR ( $p$ value $<0.05)$. PAL and mid-upper arm circumference $(\mathrm{MAC})$ were higher in participants without dyslipidemia ( $p$-value $<0.001)$. Unsurprisingly mean serum TC, TG, and LDL-C, and FBG were higher in participants with dyslipidemia; and serum HDL-C was lower than in participants without dyslipidemia $(p$-value $<0.001)$. Systolic and diastolic blood pressures, the prevalence of hypertension, diabetes, and family history of CVD were higher in the participants with dyslipidemia ( $p$-value $<0.001)$.
'A higher percentage of subjects in the non dyslipidemia group were taking lipid lowering drugs, and a higher percentage of those with dyslipidemia consumed antihypertensive drugs ( $p$-value $<0.001)$. The HEI was higher among individuals with dyslipidemia, while total energy intake was lower among this group compared to those without dyslipidemia ( $p$-value $<0.001)$.

In Table 3, we compare the 3582 men to 5116 women based on having dyslipidemia and its components. We found that the prevalence of dyslipidemia and its components were higher in women, except for serum TG concentration which was higher among men $(p$-value $<0.001)$.

In Table 4, we have evaluated the association between dyslipidemia and its components with the occurrence of CVD (myocardial infarction [MI], stable angina [SA], and unstable angina $[\mathrm{UA}])$. In the total population, according to crude HR, the risk of total CVD was associated with dyslipidemia and high levels of LDL-C, TC, and TG ( $p$ value $<0.05)$. The risk of MI was associated with higher mean levels of LDL-C and TC ( $p$-value $<0.05$ ), whilst the risk of SA was associated with high levels of TC ( $p$-value $<0.05$ ); though this was no longer the case after adjusting for several confounding factors.

In men, according to crude HR and multivariable HR, a high serum TC was associated with an increased risk of MI ( $p$-value $<0.05$ ). In women, according to crude HR dyslipidemia, high levels of LDL-C, TC, and TG were positively associated with total CVD events ( $p$ value $<0.05$ ). The risk of SA was associated with high TC, while dyslipidemia and high TG concentrations were associated with an increased risk of UA ( $p$-values $<0.05$ ). However after adjusting for potential confounding factors, the significance of these associations did not remain.

\section{Discussion}

Our study aimed to investigate the association of dyslipidemia and its components with CVD incidence after 6 years of follow-up. At this timepoint, 2.68\% $(n=233)$ had developed CVD, and dyslipidemia was highly prevalent in the total population; estimated to be $85.35 \%$ ( $n=$ 7424). However, our findings were different before and after multivariable adjustment. According to the crude HR, serum LDL-C, TC, and TG levels were positively associated with total CVD risk among the total population and women. However, after adjustment for confounding factors, including diet, these associations were no longer significant, apart for a high serum TC that significantly increased the risk of MI in men.

Dyslipidemia and lipid oxidation are thought to be important determinants of atherosclerosis that leads to CVD [11]. We aimed to study the relationship between dyslipidemia and CVD in an Iranian adult cohort to find the relationship between dyslipidemia and its components with 
Table 1 Baseline characteristic of participants who did or did not develop cardiovascular disease at follow-up

\begin{tabular}{|c|c|c|c|}
\hline \multirow[t]{2}{*}{ Variable } & \multicolumn{2}{|l|}{ CVD } & \multirow{2}{*}{$\begin{array}{l}p- \\
\text { value }\end{array}$} \\
\hline & No $(n=8465)$ & Yes $(n=233)$ & \\
\hline Male, \% (N) & $41(3473)$ & 47 (109) & 0.069 \\
\hline Age, year & $47.85 \pm 8.12$ & $54.31 \pm 6.98$ & $<0.001$ \\
\hline \multicolumn{4}{|l|}{ Marriage status, \% (N) } \\
\hline Married & 93.80 (7941) & $92.20(215)$ & \multirow[t]{2}{*}{0.326} \\
\hline Single/divorced/widow & $6.20(523)$ & $7.80(18)$ & \\
\hline \multicolumn{4}{|l|}{ Education level, \% (N) } \\
\hline Low (trade school) & $52.40(4432)$ & $65.90(154)$ & \\
\hline Moderate (high school) & $35.90(3033)$ & $25(58)$ & \multirow[t]{2}{*}{$<0.001$} \\
\hline High (university) & $11.70(989)$ & $9.10(21)$ & \\
\hline \multicolumn{4}{|l|}{ Smoking status, \% (N) } \\
\hline Non smoker & $69.60(5883)$ & $62.10(145)$ & \\
\hline Ex - smoker & $9.70(823)$ & $16.80(39)$ & \multirow[t]{2}{*}{0.001} \\
\hline Current smoker & $20.70(1752)$ & $21.10(49)$ & \\
\hline PAL & $1.59 \pm 0.28$ & $1.53 \pm 0.28$ & 0.001 \\
\hline Weight (kg) & $71.85 \pm 12.84$ & $74.15 \pm 12.49$ & 0.007 \\
\hline Height (cm) & $160.81 \pm 9.14$ & $160.27 \pm 9.17$ & 0.374 \\
\hline BMI $\left(\mathrm{kg} / \mathrm{m}^{2}\right)$ & $27.83 \pm 4.70$ & $28.92 \pm 4.54$ & $<0.001$ \\
\hline$W C(\mathrm{~cm})$ & $95.10 \pm 12.01$ & $99.05 \pm 10.59$ & $<0.001$ \\
\hline $\mathrm{HC}(\mathrm{cm})$ & $103.65 \pm 9.26$ & $104.29 \pm 9.41$ & 0.298 \\
\hline WHR & $0.92 \pm 0.08$ & $0.95 \pm 0.07$ & $<0.001$ \\
\hline MAC (cm) & $30.58 \pm 3.94$ & $30.62 \pm 3.62$ & 0.865 \\
\hline Dyslipidemia & $66(5590)$ & $78.90(183)$ & $<0.001$ \\
\hline Cholesterol (mg/dl) & $190.56 \pm 38.56$ & $199.83 \pm 42.16$ & $<0.001$ \\
\hline TG (mg/dl) & $120(84,171)$ & $139(101.25,215.50)$ & $<0.001$ \\
\hline LDL-C (mg/dl) & $115.89 \pm 34.96$ & $122.35 \pm 35.59$ & 0.006 \\
\hline $\mathrm{HDL}-\mathrm{C}(\mathrm{mg} / \mathrm{dl})$ & $42.82 \pm 9.87$ & $40.21 \pm 9.05$ & $<0.001$ \\
\hline FBG (mg/dl) & $91.45 \pm 36.92$ & $119.45 \pm 63.10$ & $<0.001$ \\
\hline SBP $(\mathrm{mmHg})$ & $121.26 \pm 18.22$ & $134 \pm 20.88$ & $<0.001$ \\
\hline $\mathrm{DBP}(\mathrm{mmHg})$ & $79.01 \pm 11.74$ & $83.77 \pm 10.69$ & $<0.001$ \\
\hline HTN, \% & $22.60(1907)$ & $44.80(104)$ & $<0.001$ \\
\hline $\mathrm{DM}, \%$ & $8.30(704)$ & $28(65)$ & $<0.001$ \\
\hline Lipid lowering drug, \% (N) & $2.40(203)$ & $12.90(30)$ & $<0.001$ \\
\hline Anti-hypertensive drug, \% (N) & $4.10(347)$ & $16.40(38)$ & $<0.001$ \\
\hline Family history of CVD, \% (N) & $34.90(2929)$ & $44.30(101)$ & 0.003 \\
\hline HEl & $55.27 \pm 8.56$ & $55.71 \pm 8.27$ & 0.433 \\
\hline Total energy intake (kcal/day) & $2022.46 \pm 679.19$ & $1945.66 \pm 708.74$ & 0.148 \\
\hline
\end{tabular}

Abbreviations: PAL physical activity level, BMI body mass index, WC waist circumference, $H C$ hip circumference, WHR waist-to-hip ratio, $M A C$ mid- upper arm circumference, SBP systolic blood pressure, DBP diastolic blood pressure, FBG fasting blood glucose, $T G$ triglyceride, $L D L-C$ low density lipoprotein cholesterol, $H D L-$ $C$ high density lipoprotein cholesterol, and $H E I$ healthy eating index

Data are presented as means \pm standard deviations and median (interquartile range) for continuous variables and as percentages for categorical variables. Independent sample t-test and Mann-Whitney $U$ test were used where appropriate

Hypertension was defined as systolic blood pressure $\geq 140 \mathrm{mmHg}$, diastolic blood pressure $\geq 90 \mathrm{mmHg}$

Diabetes was defined as fasting blood glucose $\geq 126 / \mathrm{mg} / \mathrm{dl}$

Dyslipidemia was defined as total cholesterol $\geq 200$, or triglycerides $\geq 150$, or low-density lipoprotein cholesterol (LDL-C) $\geq 130$, or high-density lipoprotein cholesterol (HDL-C) $<40$ (for men) and HDL-C $<50$ (for women)

There are some missing data regarding marriage status (no CVD: 2), education level (no CVD: 12), smoking status (no CVD: 8), HTN (no CVD: 29) and family history of CVD (no CVD: 67, CVD: 4) 
Table 2 Baseline characteristics of participants based on the presence or absence of dyslipidemia

\begin{tabular}{|c|c|c|c|}
\hline \multirow[t]{2}{*}{ Variables } & \multirow{2}{*}{$\begin{array}{l}\text { Dyslipidemia } \\
\text { Yes }(n=7424)\end{array}$} & \multirow{2}{*}{$\begin{array}{l}\text { Dyslipidemia } \\
\text { No }(n=1273)\end{array}$} & \multirow[t]{2}{*}{$P$-value } \\
\hline & & & \\
\hline Age, year & $48.18 \pm 8.10$ & $47.10 \pm 8.42$ & $<0.001$ \\
\hline \multicolumn{4}{|l|}{ Marriage status, \%(N) } \\
\hline Married & $93.50(6941)$ & $95.30(1213)$ & \multirow[t]{2}{*}{0.016} \\
\hline Single/divorced/widow & $6.50(481)$ & $4.70(60)$ & \\
\hline \multicolumn{4}{|l|}{ Education level, \% (N) } \\
\hline Low (trade school) & $52.70(3909)$ & $53.10(675)$ & \\
\hline Moderate (high school) & $35.60(2641)$ & $35.40(450)$ & \multirow[t]{2}{*}{0.976} \\
\hline High (university) & $11.60(863)$ & $11.60(147)$ & \\
\hline \multicolumn{4}{|l|}{ Smoking status, \% (N) } \\
\hline Non smoker & $69.60(5162)$ & $67.90(864)$ & \\
\hline Ex - smoker & $9.80(724)$ & $10.80(138)$ & \multirow[t]{2}{*}{0.384} \\
\hline Current smoker & $20.60(1531)$ & $21.20(270)$ & \\
\hline PAL & $1.58 \pm 0.28$ & $1.65 \pm 0.31$ & $<0.001$ \\
\hline Weight (kg) & $72.61 \pm 12.77$ & $67.86 \pm 12.49$ & $<0.001$ \\
\hline Height (cm) & $160.52 \pm 9.10$ & $162.42 \pm 9.25$ & $<0.001$ \\
\hline BMI $\left(\mathrm{kg} / \mathrm{m}^{2}\right)$ & $28.21 \pm 4.61$ & $25.79 \pm 4.69$ & $<0.001$ \\
\hline WC (cm) & $95.94 \pm 11.84$ & $90.91 \pm 11.95$ & $<0.001$ \\
\hline $\mathrm{HC}(\mathrm{cm})$ & $104.10 \pm 9.22$ & $101.13 \pm 9.12$ & $<0.001$ \\
\hline WHR & $0.92 \pm 0.08$ & $0.90 \pm 0.08$ & $<0.001$ \\
\hline MAC (cm) & $30.07 \pm 3.73$ & $30.07 \pm 4.91$ & $<0.001$ \\
\hline Cholesterol (mg/dl) & $194.51 \pm 39.96$ & $169.20 \pm 19.20$ & $<0.001$ \\
\hline $\mathrm{TG}(\mathrm{mg} / \mathrm{dl})$ & $152.52 \pm 95.62$ & $83.14 \pm 28.28$ & $<0.001$ \\
\hline LDL-C (mg/dl) & $119.45 \pm 35.78$ & $96.34 \pm 21.07$ & $<0.001$ \\
\hline $\mathrm{HDL}-\mathrm{C}(\mathrm{mg} / \mathrm{dl})$ & $41.17 \pm 9.27$ & $51.92 \pm 8.05$ & $<0.001$ \\
\hline FBG $(\mathrm{mg} / \mathrm{dl})$ & $93.43 \pm 39.73$ & $85 \pm 25.69$ & $<0.001$ \\
\hline $\mathrm{SBP}(\mathrm{mmHg})$ & $121.99 \pm 18.53$ & $119.29 \pm 17.52$ & $<0.001$ \\
\hline $\mathrm{DBP}(\mathrm{mmHg})$ & $79.38 \pm 11.90$ & $77.73 \pm 10.65$ & $<0.001$ \\
\hline HTN, \% (N) & $23.90(1767)$ & $19.20(243)$ & $<0.001$ \\
\hline $\mathrm{DM}, \%(\mathrm{~N})$ & $9.80(724)$ & $3.50(45)$ & $<0.001$ \\
\hline Lipid lowering drug, \% (N) & $0.90(11)$ & $3(222)$ & $<0.001$ \\
\hline Anti-hypertensive drug, \% (N) & $4.80(355)$ & $2.40(30)$ & $<0.001$ \\
\hline Family history of CVD, \% (N) & $36.10(2655)$ & $29.70(375)$ & $<0.001$ \\
\hline HEl & $55.44 \pm 8.54$ & $54.34 \pm 8.56$ & $<0.001$ \\
\hline Total energy intake (kcal/day) & $2002.03 \pm 654.9$ & $2126.49 \pm 806.62$ & $<0.001$ \\
\hline
\end{tabular}

Abbreviations: PAL physical activity level, BMI body mass index, WC waist circumference, $H C$ hip circumference, WHR waist-to-hip ratio, $M A C$ mid- upper arm circumference, SBP systolic blood pressure, $D B P$ diastolic blood pressure, FBG fasting blood glucose, $T G$ triglyceride, $L D L-C$ low density lipoprotein cholesterol, $H D L-$ $C$ high density lipoprotein cholesterol, and $H E I$ healthy eating index

Data are presented as means \pm standard deviations for continuous variables and as percentages for categorical variables

Hypertension was defined as systolic blood pressure $\geq 140 \mathrm{mmHg}$, diastolic blood pressure $\geq 90 \mathrm{mmHg}$

Diabetes was defined as fasting blood glucose $\geq 126 / \mathrm{mg} / \mathrm{dl}$

Dyslipidemia was defined as total cholesterol $\geq 200$, or triglycerides $\geq 150$, or low-density lipoprotein cholesterol (LDL-C) $\geq 130$, or high-density lipoprotein cholesterol (HDL-C) $<40$ (for men) and $\mathrm{HDL}-\mathrm{C}<50$ (for women)

There are some missing data regarding marriage status (dyslipidemia patients: 2) education level (dyslipidemia patients: 17 , healthy controls: 9 ), smoking status (dyslipidemia patients: 7, healthy controls: 1), HTN (dyslipidemia patients: 24, healthy controls: 5) and family history of CVD (dyslipidemia patients: 62 , healthy controls: 9)

an incidence of CVD, as there have been inconsistent reports concerning this relationship globally.
There was a significant association between LDL-C and CVD risk in the study population using unadjusted 
Table 3 The prevalence of dyslipidemia and its components among the study population

\begin{tabular}{llllll}
\hline & Dyslipidemia & High LDL-C & High TC & High TG & Low HDL-C \\
\hline Total population $(n=8698)$ & $85.40(7424)$ & $32.30(2811)$ & $38(3309)$ & $33.90(2947)$ & $65.80(57.19)$ \\
Men $(n=3582)$ & $80.30(2877)$ & $29.80(1067)$ & $34.10(1223)$ & $36.90(1321)$ & $55.60(1990)$ \\
Women $(n=5116)$ & $88.90(4547)^{* * *}$ & $34.10(1744)^{* * *}$ & $40.80(2086)^{* * *}$ & $31.80(1626)^{* * *}$ & $72.90(3729)^{* * *}$ \\
\hline
\end{tabular}

Abbreviations: $L D L-C$ low density lipoprotein cholesterol, $T C$ total cholesterol, $T G$ triglyceride, HDL-C high density lipoprotein cholesterol

*** From comparing women with men $(P<0.001)$

data analysis. LDL-C is considered to be a major risk factor in the incidence of revascularisations, ischaemic strokes, atherothrombotic process and cardiovascular death [46], and cardiovascular guidelines in the US, and also European consider LDL-C as an important modifiable risk factor $[47,48]$. This is supported by numerous trials including two recent clinical outcome trials of proprotein convertase subtilisin/kexin 9 (PCSK9) inhibitors that increase the expression of the LDL-C receptor on hepatocytes as well as LDL-C clearance by the liver [49]. These studies have shown that the risk of CVD was reduced substantially in patients with high-risk of atherosclerotic cardiovascular disease (ASCVD) on statin therapy $[50,51]$.

Wallace et al. and Wilson et al. have demonstrated a direct relationship between serum LDL-C and CVD incidence $[52,53]$. It has also been shown that an increased level of TC (hypercholesterolemia), particularly LDL-C promotes the atherosclerosis process, leading to the deposition of cholesterol and fatty acids in the artery wall, whilst HDL-C is usually considered to be protective and returns cholesterol to the liver $[2,3,19,27]$.

After adjustment for confounding factors, high LDL-C levels were not found to be related to the risk of heart failure among the Copenhagen General Population Study and the Copenhagen City Heart Study [54]. Varbo A et al. reported that although remnant cholesterol and LDL-C would cause CVD events to a similar degree, remnant cholesterol causes more severe form of atherosclerosis compared to LDL-C [54]. In the current study high LDL-C level were associated with an increased risk of total CVD before adjusting. After adjusting for all possible confounding factors, these associations were no longer significant. Inconsistent results regarding the relationship between CVD risk and dyslipidemia might be related to the inclusion of different confounding factors in the data analysis. For example, Cromwell et al. adjusted their data only for age, gender, SBP, smoking, and lipid-lowering drugs [55]; and Berg et al. adjusted for age, gender, BMI, smoking, alcohol, diabetes mellitus and lipid-lowering drugs [56].

Previous studies have demonstrated a positive relationship between both a higher LDL-C and lower HDL-C with an increased risk of CVD [52, 53, 57]. These studies had longer follow-up duration and also considered some of the predisposing genetic factors. These inconsistent results may be attributed to the differences in the study population that include: sample size, ethnicity, and environmental factors. Niroumand and coworkers in Iran [3] assessed the atherogenic Index of plasma (AIP) according to the formula, log (TG/HDL-C), in a crosssectional study [3]. Elevated levels of TG were found to increase the risk of CVD among men more than women, though the role of TG in the pathogenesis of CVD and atheroma formation is still not clear. Nevertheless, it may be related to the cholesterol content of triglyceriderich lipoproteins rather than the role of TG particles [58, 59]. However, we found no significant association between TG and CVD events in the present study.

We found no significant relationship between serum HDL-C on the incidence of CVD. Whilst, Freitas et al. have reported that low HDL-C is a risk factor for the development of CVD in the elderly [60], a systematic review and meta-analysis reported that increased HDL-C levels was not associated with a reduced risk CVD or CVD mortality [61]. It is possible that VLDL-C and IDL$\mathrm{C}$ are important CVD risk factors in our population; that is non-HDL cholesterol may be associated with an increased the risk of CVD events in our population sample. Lawler et al. showed that participants who consumed statins had lower risk of CVDs by their effects on reducing VLDL-C to a greater extent than LDL-C concentrations [62]. Some studies show that decreasing LDL-C levels, and increasing the size of HDL-C particles, or serum HDL levels do not reduce risk of the CAD [63, 64]. Studies of HDL-C function have also aimed to assess the role of HDL-C in the incidence of CVD events [65]. Recent studies have shown that differences in HDL-C function may be associated with altered cholesterol efflux from cells and may also be independent markers of CVD risk [66, 67]. However, high levels of serum lipoproteins are important risk factors involved in CVD risk calcific aortic valve stenosis, and stroke [68, 69].

We were not able to investigate the association between serum apolipoprotein concentrations on the risk of CVD, which reported previously; Walldius et al. showed that an enhanced level of apolipoprotein B and a reduced level of apolipoprotein $\mathrm{A} 1$ are strong predictors of CVD risk [70]. LDL-C, IDL-C, and VLDL-C are apolipoprotein-B containing particles [71]. Cui et al. have reported that serum non-HDL-C is a stronger 
Table 4 Hazard ratios (95\% Cls) for cardiovascular disease events associated with dyslipidemia and its components

\begin{tabular}{|c|c|c|c|c|c|}
\hline & Dyslipidemia & High LDL-C & High TC & High TG & Low HDL-C \\
\hline \multicolumn{6}{|l|}{ Total population } \\
\hline \multicolumn{6}{|l|}{ Total CVD } \\
\hline Crude HR (95\%Cl) & $1.81(1.15-2.87)^{*}$ & $1.54(1.19-2)^{* *}$ & $1.53(1.18-1.98)^{* *}$ & $1.57(1.21-2.03)^{* *}$ & $1.15(0.87-1.52)$ \\
\hline Multivariable HR $(95 \% \mathrm{Cl})^{*}$ & $1.14(0.68-1.89)$ & $1.16(0.85-1.59)$ & $0.93(0.68-1.26)$ & $1.13(0.82-1.55)$ & $0.96(0.69-1.33)$ \\
\hline \multicolumn{6}{|l|}{ Ml } \\
\hline Crude HR (95\%Cl) & $2.12(0.65-6.89)$ & $1.91(1.03-3.55)^{*}$ & $2(1.07-3.73)^{*}$ & $1.77(0.95-3.30)$ & $1.08(0.56-2.10)$ \\
\hline Multivariable HR $(95 \% \mathrm{Cl})^{*}$ & $1.90(0.44-8.07)$ & $1.65(0.83-3.30)$ & $1.46(0.72-2.95)$ & $1.52(0.75-3.09)$ & $0.80(0.38-1.66)$ \\
\hline \multicolumn{6}{|l|}{ SA } \\
\hline Crude HR $(95 \% \mathrm{Cl})$ & $1.24(0.62-2.49)$ & $1.52(0.96-2.41)$ & $1.73(1.10-2.73)^{*}$ & $1.50(0.95-2.37)$ & $1.23(0.75-2.02)$ \\
\hline Multivariable HR $(95 \% \mathrm{Cl})^{*}$ & $0.90(0.40-2.04)$ & $1.10(0.61-1.97)$ & $1.02(0.57-1.81)$ & $1.14(0.63-2.05)$ & $1(0.55-1.83)$ \\
\hline \multicolumn{6}{|l|}{ UA } \\
\hline Crude HR (95\%Cl) & $2.37(1.15-4.85)$ & $1.43(0.99-2.06)$ & $1.31(0.92-1.89)$ & $1.58(1.10-2.26)$ & $1.14(0.77-1.68)$ \\
\hline Multivariable HR $(95 \% \mathrm{Cl})^{*}$ & $1.16(0.55-2.43)$ & $1.03(0.66-1.61)$ & $0.73(0.47-1.14)$ & $1.01(0.65-1.57)$ & $1.01(0.63-1.62)$ \\
\hline \multicolumn{6}{|l|}{ Men } \\
\hline \multicolumn{6}{|l|}{ Total CVD } \\
\hline Crude HR (95\%Cl) & $1.43(0.84-2.43)$ & $1.37(0.93-2.03)$ & $1.36(0.93-1.99)$ & $1.40(0.96-2.05)$ & $1.01(0.69-1.48)$ \\
\hline Multivariable HR $(95 \% \mathrm{Cl})^{*}$ & $0.95(0.53-1.71)$ & $1.13(0.71-1.81)$ & $1(0.63-1.59)$ & $1.49(0.94-2.35)$ & $0.90(0.57-1.41)$ \\
\hline \multicolumn{6}{|l|}{$\mathrm{Ml}$} \\
\hline Crude HR (95\%Cl) & $1.81(0.54-6.03)$ & $1.86(0.84-4.10)$ & $2.46(1.12-5.43)^{*}$ & $2.19(0.99-4.82)$ & $1.02(0.46-2.24)$ \\
\hline Multivariable HR $(95 \% \mathrm{Cl})^{*}$ & $1.95(0.45-8.51)$ & $2.22(0.94-5.26)$ & $2.71(1.12-6.57)^{*}$ & $2.35(0.94-5.86)$ & $0.85(0.36-2.04)$ \\
\hline \multicolumn{6}{|l|}{ SA } \\
\hline Crude HR (95\%Cl) & $0.86(0.35-2.12)$ & $1(0.44-2.28)$ & $1.14(0.52-2.49)$ & $1.38(0.64-2.94)$ & $1(0.47-2.13)$ \\
\hline Multivariable HR $(95 \% \mathrm{Cl})^{*}$ & $0.58(0.20-1.66)$ & $0.66(0.22-2.03)$ & $0.62(0.22-1.75)$ & $1.48(0.56-3.91)$ & $0.83(0.33-2.11)$ \\
\hline \multicolumn{6}{|l|}{ UA } \\
\hline Crude HR (95\%Cl) & $1.75(080-3.87)$ & $1.38(0.81-2.37)$ & $1.13(0.66-1.93)$ & $1.16(0.68-1.97)$ & $1.02(0.61-1.72)$ \\
\hline Multivariable HR $(95 \% \mathrm{Cl})^{*}$ & $0.91(0.40-2.11)$ & $1.01(0.51-1.98)$ & $0.71(0.36-1.39)$ & $1.18(0.62-2.24)$ & $0.95(0.50-1.81)$ \\
\hline \multicolumn{6}{|l|}{ Women } \\
\hline \multicolumn{6}{|l|}{ Total CVD } \\
\hline Crude HR (95\%Cl) & $3.71(1.37-10.04)^{*}$ & $1.74(1.22-2.48)^{* *}$ & $1.75(1.23-2.50)^{* *}$ & $1.70(1.19-2.42)^{* *}$ & $1.52(0.97-2.38)$ \\
\hline Multivariable HR $(95 \% \mathrm{Cl})^{*}$ & $1.95(0.61-6.24)$ & $1.19(0.77-1.82)$ & $0.83(0.53-1.28)$ & $0.80(0.51-1.25)$ & $1.12(0.67-1.89)$ \\
\hline \multicolumn{6}{|l|}{$\mathrm{Ml}$} \\
\hline Crude HR (95\%Cl) & $-a$ & $2.23(0.81-6.14)$ & $1.67(0.60-4.60)$ & $1.08(0.37-3.16)$ & $2.42(0.55-10.74)$ \\
\hline Multivariable HR $(95 \% \mathrm{Cl})^{*}$ & $\_$ & $1.31(0.40-4.26)$ & $0.72(0.21-2.41)$ & $0.67(0.21-2.20)$ & $1.14(0.24-5.49)$ \\
\hline \multicolumn{6}{|l|}{ SA } \\
\hline Crude HR (95\%Cl) & $1.84(0.57-5.93)$ & $1.87(1.06-.31)^{*}$ & $2.16(1.20-3.86)^{*}$ & $1.61(0.90-2.87)$ & $1.38(0.68-2.77)$ \\
\hline Multivariable HR $(95 \% \mathrm{Cl})^{*}$ & $1.38(0.32-5.92)$ & $1.30(0.64-2.67)$ & $1.18(0.57-2.46)$ & $0.92(0.43-1.97)$ & $1.08(0.47-2.45)$ \\
\hline \multicolumn{6}{|l|}{ UA } \\
\hline Crude HR (95\%Cl) & $7.55(1.05-54.46)^{*}$ & $1.51(0.91-2.49)$ & $1.56(0.95-2.57)$ & $2.03(1.23-3.4)^{* *}$ & $1.52(0.81-2.86)$ \\
\hline Multivariable HR $(95 \% \mathrm{Cl})^{*}$ & $2.75(0.37-20.22)$ & $1.06(0.57-1.94)$ & $0.66(0.36-1.21)$ & $0.77(0.41-1.43)$ & $1.20(0.57-2.55)$ \\
\hline
\end{tabular}

Abbreviations: CVD cardiovascular disease, $M I$ myocardial infarction, $S A$ stable angina, $U A$ unstable angina, $H R$ hazard ratio, $C l$ confidence interval Dyslipidemia was defined as total cholesterol $\geq 200$, or triglycerides $\geq 150$, or low-density lipoprotein cholesterol (LDL-C) $\geq 130$, or high-density lipoprotein cholesterol (HDL-C) $<40$ (for men) and HDL-C $<50$ (for women)

*Multivariable HRs were adjusted for age, body mass index (BMI), family history of cardiovascular disease, smoking status (non-smoker, ex-smoker and current smoker), lipid lowering drug, anti-hypertensive drug, diabetes mellitus, hypertension, HEl, and total energy intake

a There was no $\mathrm{Ml}$ event in this category

* $P$-value $<0.05, * *$-value $<0.01, * * *$-value $<0.001$ 
predictor of CVD mortality than LDL-C [72]; because it measures all of the potentially atherogenic lipid fractions (LDL-C, IDL-C, VLDL-C, and VLDL remnants).

Wallace et al. demonstrated the effect of high LDL-C on the incidence coronary disease, by demonstrating an association between serum LDL-C levels and singlenucleotide polymorphisms (SNPs) in gene variants of the Proline/serine-rich coiled-coil protein 1 (PSRC1) and Cadherin EGF LAG seven-pass G-type receptor 2 (CELSR2) [52]. Whilst we did not undertake a genetic analysis in our study we did evaluate their family history of CVD. Lloyd-Jones et al. found that the occurrence of parental CVD is an independent predictor of offspring CVD events in middle-aged men and women in a cohort study [57]. Therefore, genetic factors play an important role in the occurrence of dyslipidemia and also CVD events.

Additionally, previous studies showed that unhealthy diets with higher fat and calorie can impose CVD by the effect of dyslipidemia [15], we did not find any relationship between the occurrence of CVD and the quality of diet (HEI).

One strength of our cohort study was that it was performed in a large sample $(n=8698)$. Second, the associations were adjusted for several potential confounding factors, including diet. Also, some limitations of the current study must be considered. Although the great sample size was used in the current study compared to previous studies among the Iranian population, it was not as large as recent investigations that have been undertaken elsewhere $[3,27]$.

\section{Conclusion}

We found a significant association between total cholesterol and MI risk in this prospective cohort study among middle-aged men of Iran, in the city of Mashhad. Nevertheless, mechanisms that involved in increasing the risk of CVD through lipid profile components are unclear and more studies are needed to determining them.

\footnotetext{
Abbreviations

AIP: Atherogenic Index of Plasma; ANOVA: Analysis of variance; BMI: Body mass index; CELSR2: Cadherin EGF LAG seven-pass G-type receptor 2; Cl: Confidence interval; CT: Computed Tomography; CVD: Cardiovascular disease; DBP: Diastolic blood pressure; DH: Drug history; ECG: Electrocardiogram; ETT: Exercise Tolerance Test; FBG: Fasting blood glucose; FH: Family history; HC: Hip circumference; HDL-C: High-density lipoprotein cholesterol; HR: Hazard ratio; HTN: Hypertension; IDL: Intermediate density lipoproteins; LDL-C: Low-density lipoprotein cholesterol; MAC: Mid-upper arm circumference; MASHAD: Mashhad stroke and heart atherosclerotic disorder; MI: Myocardial infarction; PSRC1: Proline/ serine-rich coiled-coil protein 1; SA: Stable angina; SBP: Systolic blood pressure; SNPs: Single-nucleotide polymorphisms; TC: Total cholesterol; TG: Triglycerides; US: Unstable angina; VLDL: Very low-density lipoproteins; WC: Waist circumference; WHO: World Health Organization; WHR: Waist-tohip ratio
}

\section{Acknowledgements}

We would like to thank Mashhad University of Medical Science Research Council for their financial supports. The approval number from the constituted review board, the Ethics Committee of Mashhad University of Medical Sciences (MUMS) is IR.MUMS.MEDICAL.REC.1386.250.

\section{Adherence to national and international regulations}

Not applicable.

\section{Authors' contributions}

We declare that We contributed significantly towards the research study i.e., (a) conception (Zahra Asadi, and Mahdiyeh Yaghooti Khorasani), design (Reza Zare-Feyzabadi and Mahshad Hedayatnia) and/or analysis (Habibollah Esmaily and Zahra Asadi) and interpretation of data (Fatemeh Sadabadi' Maryam Mohammadi Bajgiran, Mohadese Rohban), gathering data (Marzieh Ghalandari, Mohamad saddigh ghaffari' Asa yousefi, Elnaz pouresmaeili, Mohhamad reza Besharatlou) and to (b) drafting the article (Roshanak Ghaffarian Zirak' Abolfazl Nosrati Tirkani) or revising it critically for important intellectual content (Hamideh Ghazizadeh, Hamid Reza Rahimi) and on (c) final approval of the version to be published (Mohsen Moohebati' Gordon A. Ferns and Majid Ghayour-Mobarhan). The authors read and approved the final manuscript.

\section{Funding}

This work was supported by a grant (Majid Ghayour Mobarhan) from Mashhad University of Medical Science (MUMS), Iran.

\section{Availability of data and materials}

Data sharing not applicable to this article as no datasets were generated or analyzed during the current study.

\section{Ethics approval and consent to participate}

Informed consent was obtained from all subjects using protocols approved by the Ethics Committee of the Mashhad University of Medical Sciences.

\section{Consent for publication \\ Not applicable.}

\section{Competing interests}

The authors declare that they have no competing interests.

\section{Author details}

${ }^{1}$ Department of Nutrition, Faculty of Medicine, Mashhad University of Medical Sciences, Mashhad, Iran. ${ }^{2}$ Student Research Committee, Mashhad University of Medical Sciences, Mashhad, Iran. ${ }^{3}$ Metabolic Syndrome Research Center, School of Medicine, Mashhad University of Medical Sciences, Mashhad, Iran. ${ }^{4}$ International UNESCO Center for Health-Related Basic Sciences and Human Nutrition, Department of Nutrition, School of Medicine, Mashhad University of Medical Sciences, Mashhad, Iran. ${ }^{5}$ Faculty of Medicine, Mashhad University of Medical Sciences, Mashhad, Iran. ${ }^{6}$ Cardiovascular Research Center, School of Medicine, Mashhad University of Medical Sciences, Mashhad, Iran. ${ }^{7}$ Division of Medical Education, Brighton \& Sussex Medical School, Falmer, Brighton, Sussex, UK. ${ }^{8}$ Social Determinants of Health Research Center, Mashhad University of Medical Sciences, Mashhad, Iran.

Received: 5 May 2019 Accepted: 18 February 2020

Published online: 16 March 2020

\section{References}

1. Guzzaloni G, Grugni G, Minocci A, Moro D, Morabito F. Liver steatosis in juvenile obesity: correlations with lipid profile, hepatic biochemical parameters and glycemic and insulinemic responses to an oral glucose tolerance test. Int J Obes. 2000:24(6):772.

2. Klop B, Elte JWF, Cabezas MC. Dyslipidemia in obesity: mechanisms and potential targets. Nutrients. 2013;5(4):1218-40.

3. Niroumand S, Khajedaluee M, Khadem-Rezaiyan M, Abrishami M, Juya M, Khodaee G, et al. Atherogenic index of plasma (AIP): a marker of cardiovascular disease. Med J Islam Repub Iran. 2015;29:240.

4. Brown CD, Higgins M, Donato KA, Rohde FC, Garrison R, Obarzanek E, et al. Body mass index and the prevalence of hypertension and dyslipidemia. Obes Res. 2000;8(9):605-19. 
5. Joshi SR, Anjana RM, Deepa M, Pradeepa R, Bhansali A, Dhandania VK, et al. Prevalence of dyslipidemia in urban and rural India: the ICMR-INDIAB study. PLoS One. 2014;9(5):e96808.

6. O'meara JG, Kardia SL, Armon JJ, Brown CA, Boerwinkle E, Turner ST. Ethnic and sex differences in the prevalence, treatment, and control of dyslipidemia among hypertensive adults in the GENOA study. Arch Intern Med. 2004;164(12):1313-8.

7. Tabatabaei-Malazy O, Qorbani M, Samavat T, Sharifi F, Larijani B, Fakhrzadeh H. Prevalence of dyslipidemia in Iran: a systematic review and meta-analysis study. Int J Prev Med. 2014;5(4):373.

8. Darroudi S, Saberi-Karimian M, Tayefi M, Arekhi S, Motamedzadeh Torghabeh A, Seyedzadeh Sani SMR, et al. Prevalence of combined and noncombined dyslipidemia in an Iranian population. J Clin Lab Anal. 2018; 32(8):e22579.

9. Sadeghi M, Haghdoost AA, Bahrampour A, Dehghani M. Modeling the burden of cardiovascular diseases in Iran from 2005 to 2025: the impact of demographic changes. Iran J Public Health. 2017;46(4):506.

10. Mathers CD, Loncar D. Projections of global mortality and burden of disease from 2002 to 2030. PLoS Med. 2006;3(11):e442

11. Mendis S, Puska P, Norrving B, Organization WH. Global atlas on cardiovascular disease prevention and control. Geneva: World Health Organization; 2011.

12. Ordovas JM. Genetic interactions with diet influence the risk of cardiovascular disease. Am J Clin Nutr. 2006;83(2):443S-6S.

13. Martirosyan DM, Miroshnichenko LA, Kulakova SN, Pogojeva AV, Zoloedov VI. Amaranth oil application for coronary heart disease and hypertension. Lipids Health Dis. 2007;6(1):1

14. Després J-P, Lemieux I. Abdominal obesity and metabolic syndrome. Nature. 2006;444(7121):881.

15. Tveden-Nyborg P, Birck MM, Ipsen DH, Thiessen T, de Bie FL, Lindblad MM, et al. Diet-induced dyslipidemia leads to nonalcoholic fatty liver disease and oxidative stress in Guinea pigs. Transl Res. 2016;168:146-60.

16. Hadaegh F, Harati H, Ghanbarian A, Azizi F. Association of total cholesterol versus other serum lipid parameters with the short-term prediction of cardiovascular outcomes: Tehran lipid and glucose study. Eur J Cardiovasc Prev Rehabil. 2006;13(4):571-7.

17. Proctor SD, Mamo JC. Intimal retention of cholesterol derived from apolipoprotein B100-and apolipoprotein B48-containing lipoproteins in carotid arteries of Watanabe heritable hyperlipidemic rabbits. Arterioscler Thromb Vasc Biol. 2003;23(9):1595-600.

18. Proctor SD, Vine DF, Mamo JC. Arterial retention of apolipoprotein B48-and B100-containing lipoproteins in atherogenesis. Curr Opin Lipidol. 2002;13(5): 461-70.

19. Proctor SD, Vine DF, Mamo JC. Arterial permeability and efflux of apolipoprotein B-containing lipoproteins assessed by in situ perfusion and three-dimensional quantitative confocal microscopy. Arterioscler Thromb Vasc Biol. 2004;24(11):2162-7.

20. Reiner Ž. Hypertriglyceridaemia and risk of coronary artery disease. Nat Rev Cardiol. 2017:14(7):401

21. Nordestgaard BG. Triglyceride-rich lipoproteins and atherosclerotic cardiovascular disease: new insights from epidemiology, genetics, and biology. Circ Res. 2016;118(4):547-63.

22. Abumrad NA, Davidson NO. Role of the gut in lipid homeostasis. Physio Rev. 2012:92(3):1061-85.

23. Navab M, Reddy ST, Van Lenten BJ, Fogelman AM. HDL and cardiovascular disease: atherogenic and atheroprotective mechanisms. Nat Rev Cardiol. 2011;8(4):222

24. Shai I, Rimm EB, Hankinson SE, Curhan G, Manson JE, Rifai N, et al. Multivariate assessment of lipid parameters as predictors of coronary heart disease among postmenopausal women: potential implications for clinical guidelines. Circulation. 2004;110(18):2824-30.

25. Bersot TP, Pépin GM, Mahley RW. Risk determination of dyslipidemia in populations characterized by low levels of high-density lipoprotein cholesterol. Am Heart J. 2003;146(6):1052-9.

26. Bittner $\mathrm{V}$. Non-high-density lipoprotein cholesterol and cardiovascular disease. Curr Opin Lipidol. 2003;14(4):367-71.

27. Glasser SP, Mosher A, Howard G, Banach M. What is the association of lipid levels and incident stroke? Int J Cardiol. 2016:220:890-4.

28. Prineas RJ, Crow RS, Zhang Z-M. The Minnesota code manual of electrocardiographic findings: Springer Science \& Business Media; 2009.
29. Luepker RV, Murray DM, Jacobs DR Jr, Mittelmark MB, Bracht N, Carlaw R, et al. Community education for cardiovascular disease prevention: risk factor changes in the Minnesota heart health program. Am J Public Health. 1994; 84(9):1383-93.

30. Norton K, Whittingham N, Carter L, Kerr D, Gore C, Marfell-Jones M. Measurement techniques in anthropometry. Anthropometrica. 1996;1:25-75.

31. Ogden $\mathrm{CL}$, Flegal KM, Carroll MD, Johnson CL. Prevalence and trends in overweight among US children and adolescents, 1999-2000. JAMA. 2002; 288(14):1728-32.

32. Huang TT-K, Harris KJ, Lee RE, Nazir N, Born W, Kaur H. Assessing overweight, obesity, diet, and physical activity in college students. J Am Col Health. 2003;52(2):83-6.

33. Expert Panel on Detection E. Executive summary of the third report of the National Cholesterol Education Program (NCEP) expert panel on detection, evaluation, and treatment of high blood cholesterol in adults (Adult Treatment Panel III). JAMA. 2001;285(19):2486.

34. Ghazizadeh H, Fazilati M, Pasdar A, Avan A, Tayefi M, Ghasemi F, et al. Association of a vascular endothelial growth factor genetic variant with serum VEGF level in subjects with metabolic syndrome. Gene. 2017:598:2731

35. Organization WH. Definition and diagnosis of diabetes mellitus and intermediate hyperglycaemia: report of a WHO/IDF consultation. 2006.

36. Giles TD, Materson BJ, Cohn JN, Kostis JB. Definition and classification of hypertension: an update. J Clin Hyper. 2009;11(11):611-4.

37. James WPT, Schofield EC. Human energy requirements. A manual for planners and nutritionists. Oxford: Oxford University Press; 1990. ISBN: 0192618911.

38. Ahmadnezhad M, Arefhosseini SR, Parizadeh MR, Tavallaie S, Tayefi M, Darroudi $S$, et al. Association between serum uric acid, high sensitive Creactive protein and pro-oxidant-antioxidant balance in patients with metabolic syndrome. BioFactors. 2018;44(3):263-71.

39. Asadi Z, Shafiee M, Sadabadi F, Heidari-Bakavoli A, Moohebati M, Khorrami $M$, et al. Association of dietary patterns and risk of cardiovascular disease events in the MASHAD cohort study. J Hum Nutr Diet. 2019;32:789-801.

40. Asadi Z, Shafiee M, Sadabadi F, Saberi-Karimian M, Darroudi S, Tayefi M, et al. Association of dietary patterns and the risk of metabolic syndrome among Iranian population: a cross-sectional study. Diabetes Metab Syndr. 2019;13(1):858-65.

41. Ahmadnezhad M, Asadi Z, Miri HH, Ferns GA, Ghayour-Mobarhan M, Ebrahimi-Mamaghani M. Validation of a short semi-quantitative food frequency questionnaire for adults: a pilot study. J Nutr Sci Diet. 2017;3:4955.

42. Guenther PM, Casavale KO, Reedy J, Kirkpatrick SI, Hiza HA, Kuczynski KJ, et al. Update of the healthy eating index: HEl-2010. J Acad Nutr Diet. 2013; 113(4):569-80

43. Feskanich D, Rockett HR, Colditz GA. Modifying the healthy eating index to assess diet quality in children and adolescents. J Am Diet Assoc. 2004; 104(9):1375-83.

44. Täger M, Peltner J, Thiele S. Evaluation of diet quality by means of the healthy eating index and its modified variants. Ernährungs Umschau. 2016; 63:110-8.

45. Khakpouri S, Safari M, Ghazizadeh H, Parizadeh SMR, Nematy M, Tayefi M, et al. The relationship between the healthy eating index and an alternate healthy eating index with the risk factors for cardiovascular disease in a population from northeastern Iran. Transl Metabol Syn Res. 2019:2(1):1-6.

46. Berman AN, Blankstein R. Optimizing dyslipidemia Management for the Prevention of cardiovascular disease: a focus on risk assessment and therapeutic options. Curr Cardiol Rep. 2019;21(9):110.

47. Grundy SM, Stone NJ, Bailey AL, Beam C, Birtcher KK, Blumenthal RS, et al. 2018 AHA/ACC/AACVPR/AAPA/ABC/ACPM/ADA/AGS/APhA/ASPC/NLA/ PCNA guideline on the management of blood cholesterol: a report of the American College of Cardiology/American Heart Association task force on clinical practice guidelines. J Am Coll Cardiol. 2019;73(24):e285-350.

48. Catapano AL, Graham I, De Backer G, Wiklund O, Chapman MJ, Drexel H, et al. 2016 ESC/EAS guidelines for the management of dyslipidaemias. Eur Heart J. 2016;37(39):2999-3058.

49. Ridker PM. LDL cholesterol: controversies and future therapeutic directions. Lancet. 2014;384(9943):607-17.

50. Sabatine MS, Giugliano RP, Keech AC, Honarpour N, Wiviott SD, Murphy SA, et al. Evolocumab and clinical outcomes in patients with cardiovascular disease. N Engl J Med. 2017;376(18):1713-22. 
51. Schwartz GG, Steg PG, Szarek M, Bhatt DL, Bittner VA, Diaz R, et al. Alirocumab and cardiovascular outcomes after acute coronary syndrome. N Engl J Med. 2018;379(22):2097-107.

52. Wallace C, Newhouse SJ, Braund P, Zhang F, Tobin M, Falchi M, et al. Genome-wide association study identifies genes for biomarkers of cardiovascular disease: serum urate and dyslipidemia. Am J Hum Genet. 2008;82(1):139-49.

53. Wilson PW, D'Agostino RB, Levy D, Belanger AM, Silbershatz H, Kannel WB. Prediction of coronary heart disease using risk factor categories. Circulation. 1998:97(18):1837-47.

54. Varbo A, Nordestgaard BG. Nonfasting triglycerides, low-density lipoprotein cholesterol, and heart failure risk: two cohort studies of 113554 individuals. Arterioscler Thromb Vasc Biol. 2018;38(2):464-72.

55. Cromwell WC, Otvos JD, Keyes MJ, Pencina MJ, Sullivan L, Vasan RS, et al. LDL particle number and risk of future cardiovascular disease in the Framingham offspring study_implications for LDL management. J Clin Lipidol. 2007;1 (6):583-92.

56. van den Berg MJ, van der Graaf Y, de Borst GJ, Kappelle LJ, Nathoe HM, Visseren FL, et al. Low-density lipoprotein cholesterol, non-high-density lipoprotein cholesterol, triglycerides, and Apolipoprotein B and cardiovascular risk in patients with manifest arterial disease. Am J Cardiol. 2016;118(6):804-10.

57. Lloyd-Jones DM, Nam B-H, D'Agostino RB Sr, Levy D, Murabito JM, Wang TJ, et al. Parental cardiovascular disease as a risk factor for cardiovascular disease in middle-aged adults: a prospective study of parents and offspring. JAMA. 2004;291(18):2204-11.

58. Nordestgaard BG, Varbo A. Triglycerides and cardiovascular disease. Lancet. 2014:384(9943):626-35.

59. Chapman MJ, Ginsberg HN, Amarenco P, Andreotti F, Borén J, Catapano AL, et al. Triglyceride-rich lipoproteins and high-density lipoprotein cholesterol in patients at high risk of cardiovascular disease: evidence and guidance for management. Eur Heart J. 2011;32(11):1345-61.

60. de Freitas EV, Brandão AA, Pozzan R, Magalhães ME, Fonseca F, Pizzi O, et al. Importance of high-density lipoprotein-cholesterol (HDL-C) levels to the incidence of cardiovascular disease (CVD) in the elderly. Arch Gerontol Geriatr. 2011;52(2):217-22.

61. Briel M, Ferreira-Gonzalez I, You JJ, Karanicolas PJ, Akl EA, Wu P, et al. Association between change in high density lipoprotein cholesterol and cardiovascular disease morbidity and mortality: systematic review and metaregression analysis. BMJ. 2009;338:b92.

62. Lawler PR, Akinkuolie AO, Harada P, Glynn RJ, Chasman DI, Ridker PM, et al. Residual risk of atherosclerotic cardiovascular events in relation to reductions in very-low-density lipoproteins. J Am Heart Assoc. 2017;6(12): e007402.

63. Angeloni E, Paneni F, Landmesser U, Benedetto U, Melina G, Lüscher TF et al. Lack of protective role of HDL-C in patients with coronary artery disease undergoing elective coronary artery bypass grafting. Eur Heart J. 2013;34(46):3557-62

64. van der Steeg WA, Holme I, Boekholdt SM, Larsen ML, Lindahl C, Stroes ES, et al. High-density lipoprotein cholesterol, high-density lipoprotein particle size, and apolipoprotein Al: significance for cardiovascular risk: the IDEAL and EPIC-Norfolk studies. J Am Coll Cardiol. 2008;51(6):634-42.

65. Rader DJ, Hovingh GK. HDL and cardiovascular disease. Lancet. 2014; 384(9943):618-25.

66. Mody P, Joshi PH, Khera A, Ayers CR, Rohatgi A. Beyond coronary calcification, family history, and C-reactive protein: cholesterol efflux capacity and cardiovascular risk prediction. J Am Coll Cardiol. 2016;67(21): 2480-7.

67. Rohatgi A, Khera A, Berry JD, Givens EG, Ayers CR, Wedin KE, et al. HDL cholesterol efflux capacity and incident cardiovascular events. N Engl J Med. 2014;371(25):2383-93.

68. Willeit P, Ridker PM, Nestel PJ, Simes J, Tonkin AM, Pedersen TR, et al. Baseline and on-statin treatment lipoprotein (a) levels for prediction of cardiovascular events: individual patient-data meta-analysis of statin outcome trials. Lancet. 2018;392(10155):1311-20.

69. Kamstrup PR, Tybjærg-Hansen A, Nordestgaard BG. Elevated lipoprotein (a) and risk of aortic valve stenosis in the general population. J Am Coll Cardiol. 2014;63(5):470-7.

70. Walldius G, Jungner I, Holme I, Aastveit AH, Kolar W, Steiner E. High apolipoprotein $\mathrm{B}$, low apolipoprotein $\mathrm{Al}$, and improvement in the prediction of fatal myocardial infarction (AMORIS study): a prospective study. Lancet. 2001;358(9298):2026-33.

71. Jiang R, Schulze MB, Li T, Rifai N, Stampfer MJ, Rimm EB, et al. Non-HDL cholesterol and apolipoprotein B predict cardiovascular disease events among men with type 2 diabetes. Diabetes Care. 2004;27(8):1991-7.

72. Cui Y, Blumenthal RS, Flaws JA, Whiteman MK, Langenberg P, Bachorik PS, et al. Non-high-density lipoprotein cholesterol level as a predictor of cardiovascular disease mortality. Arch Intern Med. 2001;161(11):1413-9.

\section{Publisher's Note}

Springer Nature remains neutral with regard to jurisdictional claims in published maps and institutional affiliations.
Ready to submit your research? Choose BMC and benefit from:

- fast, convenient online submission

- thorough peer review by experienced researchers in your field

- rapid publication on acceptance

- support for research data, including large and complex data types

- gold Open Access which fosters wider collaboration and increased citations

- maximum visibility for your research: over $100 \mathrm{M}$ website views per year

At BMC, research is always in progress.

Learn more biomedcentral.com/submissions 